\title{
Forensic DNA profiling of tropical timber species in Peninsular Malaysia.
}

\begin{abstract}
Illegal logging poses a significant threat to the sustainability of tropical forest ecosystems. By using Neobalanocarpus heimii (Dipterocarpaceae) as an example, the study assessed the feasibility of using short tandem repeats (STRs) as a tool to identify the source of illegally logged timber. Thirty natural populations of $\mathrm{N}$. heimii were profiled using 12 STRs to develop the DNA profiling databases. As the cluster analysis divided the 30 populations into three genetic clusters, corresponding to three subregions within Peninsular Malaysia. The DNA databases were characterised at the levels of population, subregion and Peninsular Malaysia. Independence tests within and among loci were violated in all the databases due to significant levels of population differentiation and inbreeding. Thus, the effects of population substructure and inbreeding should be incorporated into the calculation of random match probability. The random match probabilities estimated using subpopulation and subpopulation-cum-inbreeding models were biased in favour of the defendant, whereas the random match probabilities estimated using product rule were biased in favour of the prosecutor. The conservativeness tests showed that the subregion and Peninsular Malaysia databases were conservative, and these databases should be able to provide legal evidence for court proceedings against illegal loggers in Peninsular Malaysia.
\end{abstract}

Keyword: Dipterocarpaceae; FOF forensic; Random match probability; Neobalanocarpus heimii; Short tandem repaets (STRs). 